\title{
Association between Cyclin D1 G870A Polymorphism and the Risk of Hepatocellular Carcinoma among Egyptian Population
}

\author{
Mohamed N Elkhashab ${ }^{1}$, Mohamed M Refaey ${ }^{1}$, Mohamed I Radwan', \\ Heba F Pasha ${ }^{2}$, Hoda F Ebian ${ }^{3}$, Rodalia M Makhlouf ${ }^{4}$, Mohamed H Ibrahim ${ }^{4}$ \\ ${ }^{1}$ Tropical Medicine Department, Faculty of Medicine, Zagazig University, Egypt. \\ ${ }^{2}$ Medical Biochemistry Department, Faculty of Medicine, Zagazig University, Egypt. \\ ${ }^{3}$ Clinical Pathology Department, Faculty of Medicine, Zagazig University, Egypt. \\ ${ }^{4}$ Internal Medicine Department, Faculty of Medicine, Zagazig University, Egypt.
}

Corresponding Author Mohamed M Refaey

\section{Mobile: +2010000891 59}

\section{E mail:}

rifae2007@yahoo.com

Key words: Cyclin; HCC; polymorphism; CCND1 G870A
Background and study aim : Cyclin is a regulatory protein in cell cycle encoded by CCND1 gene, it has a role in transition of cell cycle from $\mathrm{G} 1$ phase to $\mathrm{S}$ phase. A common polymorphism is in the exon of splicing donor region $G$ to $A$ polymorphism (G 870A) of cyclin D1 result in two types of mRNA, cycline D1a and D1b. Both may cause disturbance and uncontrolled growth of the cells which may lead to high susceptibility of certain tumor development.

This polymorphism could be detected by using polymerase chain reaction (PCRRFLP) assay. Our present study was performed to demonstrate the association between G870A polymorphism in (CND1) gene and hepatocellular carcinoma (HCC) among the Egyptian population.

Patients and methods: The present study was consisting of 180 peripheral blood samples from 90 subjects diagnosed with HCV without HCC, 90 subjects diagnosed with $\mathrm{HCV}$ and HCC and 90 individual

\section{INTRODUCTION}

Hepatocellular carcinoma (HCC) is the fifth most common cancer worldwide. Also it is the most common cause of cancer related death in the world [1].

The pathogenesis of $\mathrm{HCC}$ is thought to be established through multiple and various risk factors with complex interaction between them, these factors include: chronic infection with hepatitis $B$ virus (HBV) and/or hepatitis C virus (HCV), cirrhosis, carcinogen exposure such as aflatoxin B1 (AFB1) excessive alcohol drinking and a variety of genetic factors $[2,3]$. cancer free controls matched on age, gender, smoking and DM status.

Results: Our results determined the high frequency of the alleles in the patients ( $\mathrm{G}, 40.6 \%$ and $\mathrm{A}, 30.0 \%$ ). Our results determined also the frequencies of the case subjects compared to control subjects $(59.4 \%$ versus $13.3 \%)$ and $\mathrm{P}$ value $<0.001$, also analysis of CCND1 870 gene polymorphism revealed that genotype AA and GA were significantly, more frequent in patients with HCC compared with GG genotypes as a reference among the Egyptian population as we found the odds ratios (ORS) for GA, AA and GG respectively were GG 2.27 (1.1-4.2) $\mathrm{P}=$ 0.02 , AA $6.82(1.51-7.8) \mathrm{P}=0.004$ and GG OR 1.00 with confidence interval CI: $95 \%$.

Conclusion: Our study results demonstrated that single nucleotide polymorphism of CCND1 G870A among the Egyptian population is associated with increased risk of HCC.

However chronic infection with HBV or $\mathrm{HCV}$ are the most well established environmental risk factors for HCC, only a fraction of infected patients develop HCC during their life time [4].

In Egypt there was a dramatic increase in the incidence of $\mathrm{HCC}$ parallels to the increase in incidence of $\mathrm{HCV}$ infected cases in the last few years especially genotype-4, which is the predominant genotype in Egypt with approximately $(10 \%-20 \%)$ of the population being infected [4]. 
Several single nucleotide polymorphism (SNPS) have been suggested as a risk factors for a variety of cancers including HCC [5], for multifactorial disease such as HCC, the identification of modifier genes should make it possible to define hepatocarcinogenic risk factors.

A number of studies have been suggested that the cyclin D1 870A allele is associated with susceptibility to various tumors including oral cancer [6], colorectal cancer [7] and bladder cancer $[\mathbf{8 , 9}]$.

Cyclin D1 (CCND1) is involved in the normal cycle regulation and in neoplesia where it is frequently over expressed [10].

Cyclin D1 plays an important role as it is a key of cell cycle regulatory proteins at the G1/S check point of the cell cycle. Inhibition of CCND1 often, results in cell cycle arrest whereas, overexpression of CCND1 gene may disrupt normal cell cycle control and subsequently, contributes to oncogenesis [11]. Therefore, CCND1 has been regarded as a potential target of tumor therapy [12].

Cyclin D1 protein is encoded by the CCND1 gene located on chromosome 11q13. Polymorphism in CCND1 with common $G$ to A substitution at nucleotide G870 A in exon 4 of the gene creates different splice variant transcripts cyclin D1a and cyclin D1b through an alternative splicing at G870 creates an optimal splice clonor site of polymorphism [13].

Cyclin D1 and D1b proteins differ in their $\mathrm{CooH}-$ terminus a region involved in protein degradation, both transcripts encode proteins that contain amino acids which are responsible for the function of cyclin D1 therefore, it has been demonstrated that, transcripit (b) is more likely to bypass the G1/S cell cycle check point which consequently, lead to over accumulation of cyclin D1 in the cell, which result in the propagation of unrepaired DNA damage [14].

So, CCND1G870A polymerphism may influence the individuals susceptibility for development of certain tumors. So, genotyping analysis using polymerase chain reaction restriction fragment length polymorphism (PCR-RFLP) assay to evaluate the distribution of cyclin D1 gene G870A genotypes in patient with HCV.

So, early detection of patients who are at high risk of development of HCC will facilitate early detection and better management.
Aim of the work is to investigate the distribution of cyclin D1 gene G 870A genotype among patients with $\mathrm{HCV}$ or HBV infected patients and its relation to HCC.

\section{PATIENTS AND METHODS}

\section{Study subjects:}

The study was conducted in Tropical Medicine, Internal Medicine, Medical Biochemistry and Clinical Pathology Departments in Zagazig University Hospitals from March 2013 to December 2014 with approval of ethical committee and ethical consent was taken from persons included in the study.

The study included 270 subjects divided into 3 group each including 90 subjects:

Group I: This group include (90) patients diagnosed as HCC and HCV positive.

Group II: This group include (90) patients with $\mathrm{HCV}$ cases with or without cirrhosis and without HCC.

Group III: Represents the control subjects and they neither have liver disease nor cancer .They have negative serological markers for $\mathrm{HCV}$ and HBV infections.

HCV positive patients were diagnosed with positive antibodies or positive polymerase chain reaction for HCV RNA. HCC was diagnosed by (ultrasonographic liver study, AFP assessment and positive findings following examination using Tri-phasic computed axial tomography liver study or Dynamic Contrast Enhanced Magnetic Resonance imaging (Dymic contrastenhanced MRI)[15].

Full history was taken and physical examination were done for the patients and control subjects, laboratory measurements including $\mathrm{CBC}$, liver function tests, serum creatinine, PT, INR, fasting and post prandial serum glucose level.

HBs Ag was assessed using an immunoassay, HCV Ab by $3^{\text {rd }}$ generation ELISA, HCV RNA by (PCR-RFLP).

Collection of samples was performed by taking $2 \mathrm{ml}$ of peripheral venous blood from each subjects under complete aseptic conditions and collected with dipotassium EDTA $(1 \mathrm{mg} / \mathrm{mL})$ for DNA extraction and analysis of gene polymorphism, all samples were frozen at $-20^{\circ} \mathrm{C}$ until use. 
DNA extraction and genotyping:

Genomic DNA was isolated from dipotassium EDTA $(1 \mathrm{mg} / \mathrm{ml})$ by standard proteinase $\mathrm{k}$ digestion and followed by phenol-chloroform methods by using protocols by genetic blood genomic DNA purification kit (provided by fermentas) according to manufacturer's instruction.

The CCND1 G870A genotype was determined by polymerase chain reaction-restriction fragment length polymorphism (PCR-RFLP) analysis to determine the genotype of G/A polymorphism of CCND1 gene at nucleotide 870 [16] by using specific primer sets as follow: forward 5/GTG AAG TTC ATT TCC AAT CCG C-3' in exon4 reverse 5'/CGG ACA TCA CCC TCA CTT AC3 ' in interon 4.

\section{Polymerase chain reaction restriction fragment length polymorphism analysis:}

The PCR was performed in a volume of $50 \mu \mathrm{l}$ reaction containing $25 \mu \mathrm{l}$ of $2 \mathrm{xTaq}$ PCR master mix, $10 \mathrm{p}, 1 \mu \mathrm{g}$ template DNA, $0.1-1.0 \mu \mathrm{M}$ of each primer and to $50 \mu$ water, nuclease-and then PCR cycling amplification were $10 \mathrm{~min}$. at $95^{\circ} \mathrm{C}$ followed by 35 cycles of $60 \mathrm{sec}$ at $95^{\circ} \mathrm{C}, 1 \mathrm{~min}$. at $61^{\circ} \mathrm{C}$ and $1 \mathrm{~min}$ at $72^{\circ} \mathrm{C}$ with a final elongation step at $72^{\circ} \mathrm{C}$. for $7 \mathrm{~min}$. after confirmation of successful PCR amplification by $1.5 \%$ agarose gel electrophoresis, each PCR product was digested after incubation at $37^{\circ} \mathrm{C}$ for 3 hours with $25 \mu \mathrm{l}$ endonuclease SCRF1 enzyme (from streptococcus cremoris F) were purchased from (Roche-applied-science, Germany) to ingest the amplified DNA according to the manufacture's instruction. Digested fragments were exposed to electrophoresis on $3 \%$ agarose gel containing $0.5 \mu \mathrm{g} / \mathrm{ml}$ ethilium bromide and visualized under UV illumination. PCR products with $G$ at the polymorphic site were digested into two fragments $145 \mathrm{bp}$ and 22bp while those with A were not because of the absence of a SCRFI restriction site. Sample yielding $145 \mathrm{bp}$ and $22 \mathrm{bp}$ fragments were scored as GG, those with single $167 \mathrm{bp}$ fragments as AA and 167bp and 22bp as GA. Detection of the digested samples by electrophoresis using submarine gel electrophoresis system (Pharmacia Biotech by SEMKO $\mathrm{AB}$, Sweden) and submarine chamber (Maxicell, EC360, M-E-C apparelus Co. Florida, USA). Photographed under ultraviolet transillumination.
Heralab $\mathrm{GmbH}$ laborgreate transilluminator, Germany).

\section{Statistical analysis}

SPSS 17.0 for windows (SPSS, Chicago, IL) was used to analyze data. Genotype and allele frequencies were compared between HCC patients and controls and also between $\mathrm{HCV}$ between without HCC patients using the $\mathrm{x} 2$ test. Probabilities (P) were considered statistically significant if $\mathrm{P}$-value $<0.05$.

\section{RESULTS}

This study included $90 \mathrm{HCV}$ positive patients with HCC (60 males and 30 females), $90 \mathrm{HCV}$ positive patients without HCC (64 males and 26 females) and 90 healthy control subjects (52 males and 38 females). There was no significant difference in mean age between the three studied groups. Moreover, there was no significant difference between the groups regarding sex or smoking status. However, there was a significant difference between the groups regarding presence of absence of DM $(\mathrm{P}<0.001)$ (Table 1$)$.

There were no significant difference between $\mathrm{HCV}$ positive patients with $\mathrm{HCC}$ and $\mathrm{HCV}$ positive patients without HCC regarding Child Pugh classification (Table 2, Fig. 1).

Analysis of CCND1 gene polymorphism among $\mathrm{HCV}$ positive patients with $\mathrm{HCC}$ and healthy controls (Table 3 ) revealed that the GA and AA genotypes were significant more frequent in patients with HCC, than in health controls ( $41.1 \%$ vs $33.3 \%, \mathrm{P}=0.001$ and $38.9 \%$ vs $13.3 \%$, $\mathrm{P}<0.001$ respectively). Patients with $\mathrm{HCC}$ also had higher frequencies of the allele $\mathrm{A}$ than controls $(59.4 \%$ vs $30 \%$, $(\mathrm{P}<0.001)$.

Analysis of the CCND1 gene polymorphism among $\mathrm{HCV}$ positive patients with $\mathrm{HCC}$ and HCV positive patients without HCC (Table 4) revealed that the GA and AA genotype were significantly more frequent in patients with $\mathrm{HCC}$, than in patients without HCC $(41.1 \%$ vs $34.4 \%, \mathrm{P}=0.019$ and $38.9 \%$ vs $24.4 \%, \mathrm{P}=0.003$ respectively). Patients with $\mathrm{HCC}$ also had higher frequencies of the allele $\mathrm{A}$ than patients without $\operatorname{HCC}(59.4 \%$ vs $41.7 \%, \mathrm{P}=0.001)$. 
Table (1): Demographic characteristics of the study population:

\begin{tabular}{|c|c|c|c|c|}
\hline & $\begin{array}{c}\text { HCV \& HCC cases } \\
(n=90)\end{array}$ & $\begin{array}{c}\text { HCV cases } \\
(\mathrm{n}=90)\end{array}$ & $\begin{array}{c}\text { Control cases } \\
(n=90)\end{array}$ & $\mathbf{P}$ \\
\hline Age (years) & $\begin{array}{l}55.4 \pm 12.29 \\
(38-77)\end{array}$ & $\begin{array}{c}52.0 \pm 13.17(28- \\
76)\end{array}$ & $\begin{array}{c}52.7 \pm 10.31(38- \\
73)\end{array}$ & NS\# \\
\hline \multicolumn{5}{|l|}{ Sex } \\
\hline Male & $60(66.7 \%)$ & $64(71.1 \%)$ & $52(57.8 \%)$ & \multirow{2}{*}{ NS* } \\
\hline Female & $30(33.3 \%)$ & $26(28.9 \%)$ & $38(42.2 \%)$ & \\
\hline \multicolumn{5}{|l|}{ Smoking } \\
\hline Non smoker & $55(61.1 \%)$ & $58(64.4 \%)$ & $56(62.2 \%)$ & \multirow{3}{*}{ NS* } \\
\hline Smoker & $14(15.6 \%)$ & $19(21.1 \%)$ & $24(26.7 \%)$ & \\
\hline X-smoker & $21(23.3 \%)$ & $13(14.4 \%)$ & $10(11.1 \%)$ & \\
\hline \multicolumn{5}{|l|}{ DM } \\
\hline -ve & $35(38.9 \%)$ & $36(40.0 \%)$ & $90(100 \%)$ & \multirow{2}{*}{$\begin{array}{c}<0.001^{*} \\
\text { HS }\end{array}$} \\
\hline$+\mathrm{ve}$ & $55(61.1 \%)$ & $54(60.0 \%)$ & $0(0 \%)$ & \\
\hline
\end{tabular}

Data are presented as Mean \pm SD (range) or number of cases (percentage), and evaluated by independent sample test (\#), or chi-squared tests $(*)$, respectively. NS: Not significant \& HS: highly significant

Table (2): Child Pugh classification distribution between HCV positive patients with HCC and HCV positive patients without HCC

\begin{tabular}{|c|c|c|c|}
\hline & $\begin{array}{c}\text { HCV \& HCC cases } \\
(n=90)\end{array}$ & $\begin{array}{c}\text { HCV cases } \\
(n=90)\end{array}$ & $\mathbf{P}$ \\
\hline \multicolumn{4}{|c|}{ Child Pugh classification } \\
\hline - $A$ & $15(16.7 \%)$ & $18(20.0 \%)$ & \\
\hline - $B$ & $32(35.6 \%)$ & $38(42.2 \%)$ & NS \\
\hline - $C$ & $43(47.8 \%)$ & $34(37.8 \%)$ & \\
\hline
\end{tabular}

Data are presented as number of cases (percentage), and evaluated by chi-squared test. NS: not significant.

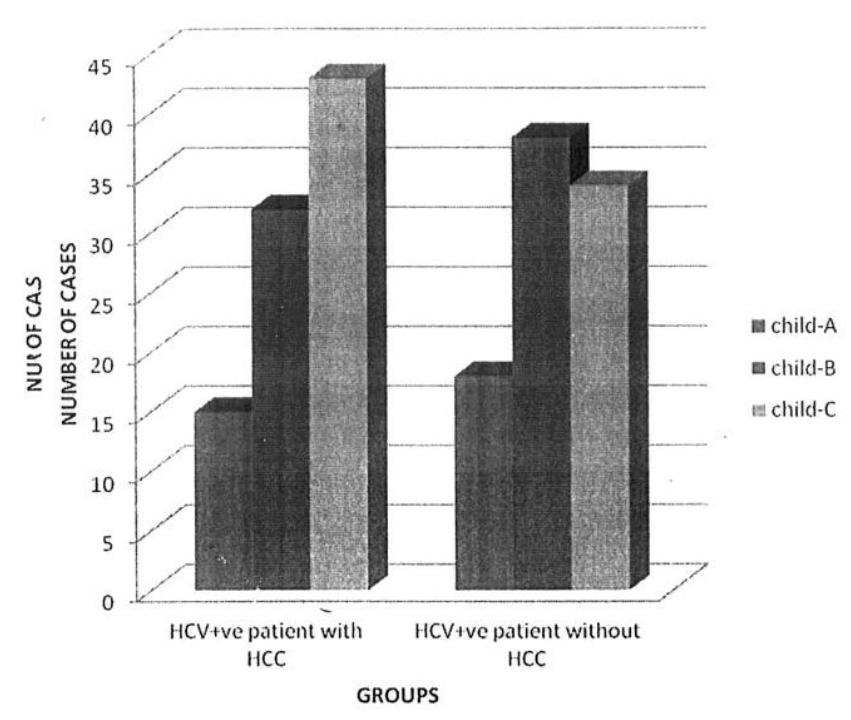

Fig. (1)

Child Pugh classification distribution between $\mathrm{HCV}$ positive patients with $\mathrm{HCC}$ and $\mathrm{HCV}$ positive patients without HCC. 
Table (3): AFP level in HCC and HCV groups

\begin{tabular}{|c|c|c|c|c|c|}
\hline & Group & No & Mean & Std. Deviation & P \\
\hline \multirow{2}{*}{ AFP } & HCV \& HCC & 90 & 1304.45 & 2484.88 & \multirow{2}{*}{$<0.05$} \\
\cline { 2 - 5 } & HCV & 90 & 70.98 & 117.97 & \\
\hline
\end{tabular}

AFP level distribution is significant as $\mathrm{p}=<0.05$.

Table (4): Distribution of the CCND1 gene polymorphism in HCV positive patients with HCC and healthy controls as regard genotypes and alleles frequency

\begin{tabular}{|c|c|c|c|c|c|}
\hline & $\begin{array}{c}\text { HCV \& HCC } \\
\text { cases } \\
(\mathbf{n}=90)\end{array}$ & $\begin{array}{c}\text { Control cases } \\
(\mathbf{n}=\%)\end{array}$ & $X^{2}$ & OR $(95 \%$ CI $)$ & $\mathbf{P}$ \\
\hline \multicolumn{6}{|c|}{ Genotype } \\
\hline GG & $18(20.0 \%)$ & $48(53.3 \%)$ & - & 1.00 (Reference) & \\
\hline GA & $37(41.1 \%)$ & $30(33.3 \%)$ & 9.6 & $2.27(1.1-4.2)$ & 0.02 \\
\hline $\mathbf{A A}$ & $35(38.9 \%)$ & $12(13.3 \%)$ & 24.6 & $6.82(1.51-7.8)$ & 0.004 \\
\hline \multicolumn{6}{|c|}{ Allele frequencies } \\
\hline $\mathbf{G}$ & $73(40.6 \%)$ & $126(70.0 \%)$ & - & 1.00 (Reference) & \\
\hline $\mathbf{A}$ & $107(59.4 \%)$ & $54(30.0 \%)$ & 30.4 & $3.4(2.21-5.2)$ & $<0.001$ \\
\hline
\end{tabular}

Data are presented a number of cases and percentage, and evaluated by Chi-squared test and relative risk/Odds rations.

Table (5): Distribution of the CCND1 gene polymorphism in HCV positive patients with HCC and $\mathrm{HCV}$ patients without $\mathrm{HCC}$ as regard genotypes and alleles frequency

\begin{tabular}{|c|c|c|c|c|c|}
\hline & $\begin{array}{c}\text { HCV + ve with } \\
\text { HCC cases } \\
(\mathbf{n = \%})\end{array}$ & $\begin{array}{c}\text { HCV +ve without } \\
\text { HCC cases } \\
\mathbf{n}(\boldsymbol{\%})\end{array}$ & $\mathbf{X}^{\mathbf{2}}$ & OR (95\% CI) & P Value \\
\hline Genotype & $18(20.0 \%)$ & $37(41.1 \%)$ & - & 1.00 (Reference) & \\
\hline GG & $37(41.1 \%)$ & $31(34.4 \%)$ & 4.9 & $2.5(1.2-5.1)$ & 0.019 \\
\hline GA & $35(38.9 \%)$ & $22(24.4 \%)$ & 8.1 & $3.3(1.5-7.1)$ & 0.003 \\
\hline AA & $73(40.6 \%)$ & $105(58.3 \%)$ & - & 1.00 (Reference) & \\
\hline Allele frequencies & $75(41.7 \%)$ & 10.7 & $2.1(1.3-3.1)$ & $<0.001$ \\
\hline G & $107(59.4 \%)$ & A &
\end{tabular}

\section{DISCUSSION}

$\mathrm{HCC}$ is the fifth most common cancer worldwide and the third most common cause of cancer related death with 600,000 patients dying from this disease every year [1]. In Egypt, there was a dramatic increase in the number of $\mathrm{HCC}$ cases in the last few years making it the fourth commonest cancer and the 2nd only in males after carcinoma of the urinary bladder [4].

Hepatitis $\mathrm{C}$ virus and hepatitis $\mathrm{B}$ virus infections are the major cause of HCC. So, identification of other risk factors and stratification of those individuals who are at increased risk for development of HCC is needed. Genetic polymorphism on many functionally critical genes has been suggested as a risk factor [17].

CCND1 gene polymorphism associated with susceptibility to various tumors such as lung, colorectal, breast and bladder cancers [7,8,9,18,]. For multifunctional disease such as HCC identification of modifier genes should make it possible to define hepato-carcinogenic risk factors.

We design this study to determine the association if any, between the risk for HCC and chronic $\mathrm{HCV}$ infection. So we investigated the association of cyclin D1 G870A polymorphism and risk of HCC in Egyptian population. As in Egypt there is a dramatic increase in the number of $\mathrm{HCC}$ 
cases in the last few years [19]. We tried to assess the relation between (CCND1G 870A) genotype and $\mathrm{HCC}$ in 270 Egyptian subjects who were divided into 3 groups each included 90 subjects (group I included $90 \mathrm{HCV}$ infected patients who developed HCC, group II included $90 \mathrm{HCV}$ infected patients without HCC and group III included 90 healthy controls).

The risk of development of HCC is high among Turkish and Chinese population respectively $[7,13,19]$. These data may support the hypothesis that gene polymorphism may have a role in pathogenesis of HCC.

We found the presence of AA allele increased the risk of HCC by 3 folds as the A allele encodes cycline D1b isoform that has longer half-life, thus, allowing over accumulation of cyclin D1 in the cell leading to premature cell passage through G1/S transition which results in genetic errors [20). CA allele also increase the risk for $\mathrm{HCC}$ by 2.2 folds [21,22].

This study included 270 Egyptian persons their ages range from 28-77 years old with mean age of 52.5 years. Although age is a surrogate of duration of infection in many patients thereby, predicting a risk of HCC. In our study age was not significant between the three groups (Table 1). These results go in hand with a previous study [19].

In every geographical area, men are more often affected by HCC than women, with higher rates of liver cancer in men having been long interpreted in sex related differences in the exposure to environmental factors known to be carcinogenic to the liver. Also gender differences could also reflect differences in interleukin 6 (IL6) productions by the liver [23].

Our study included 176 males $(65.2 \%)$ \{60 were $\mathrm{HCV}+\mathrm{ve}$ with HCC, 64 were $\mathrm{HCV}$ +ve and 52 were controls $\}$ and 94 females $(34.8 \%)$ \{30were $\mathrm{HCV}+\mathrm{ve}$ with HCC, 26 were $\mathrm{HCV}$ +ve and 38 were controls\} (Table 1). There was no significant difference in gender between the three groups. These results were in accordance with a study found that there was no significant difference between study groups as regard the gender [21]. Our study does not match with a study reported that males are at higher risk of HCC than females but the difference was not significant [24].

Epidemiologic evidence of a link between cigarette smoking and the occurrence of $\mathrm{HCC}$ was traditionally conflicting [21].
Our study included 169 non smoker persons (83\%) $\{55$ were HCV +ve with HCC, 58 were $\mathrm{HCV}+\mathrm{ve}$ and 56 controls $\}, 57$ smokers (21.13\%) \{ 14 were HCV +ve with HCC, 19 were $\mathrm{HCV}+\mathrm{ve}$ and 24 controls $\}$ and $44 \mathrm{X}$-smoker persons (16.2) \{21 were HCV +ve with HCC, 13 were $\mathrm{HCV}+\mathrm{ve}$ and $10 \mathrm{X}$-smoker controls (Table 1). Difference in smoking between study groups was not significant. Our results match with a study that found no significance between studied groups. However these results do not match with a study reported that smokers had 2.5 folds risk of HCC than non-smokers and the risk was significant [25].

Several case-control studies have shown that, on average, HCC is twice as likely to develop in persons with type 2 diabetes as compared with those who do not have diabetes [26].

Our study included 109 persons (40.3\%) who were type $2 \mathrm{DM}$ ( 55 were $\mathrm{HCV}$ +ve with $\mathrm{HCC}$, 54 were $\mathrm{HCV}+\mathrm{ve}$ and zero for controls) and 161 persons (59.6\%) without DM (35were HCV +ve with HCC, 36 were $\mathrm{HCV}+$ ve and 90 were controls). No persons were type $1 \mathrm{DM}$ in our study (Table 1). There was significant difference between the 3 groups so DM type 2 increases risk of HCC. These results agreed with a study proved that DM increases risk of HCC by four folds.

The 5-year cumulative risk for the development of HCC in patients with cirrhosis ranges between $5 \%$ and $30 \%$, depending on the cause (with the highest risk among those infected with $\mathrm{HCV}$ ), stage of cirrhosis (with the highest risk among patients with decompensated disease) [27]. Our study included 180 patients with chronic liver disease who were classified according to Child Pugh classification (Table 2). The study included 33 patients (18.3\%) with Child A (15 were HCV +ve with HCC, 18 were $\mathrm{HCV}+\mathrm{ve}$ ), 70 patients (38.8\%) with Child B (32 were HCV +ve with HCC, 38 were HCV +ve and 77 patient (42.7\%) with Child C (43 were HCV +ve with HCC, 34 were $\mathrm{HCV}+\mathrm{ve})$. There is no significant difference between HCC and HCV groups as regard Child Pugh classification.

AFP was the most serological test used in surveillance for HCC. In our study the AFP level mean was 1305 in HCC group and 71 in HCV group (Table 3). There was significant difference between $\mathrm{HCC}$ and $\mathrm{HCV}$ groups.

Variety of different cancers where it induces proliferation. A common $\mathrm{G}$ to A polymorphism 
(G870A) in the splice donor region of exon 4 of cyclin D1 (CCND1) gene generates two mRNAs (cyclin D1a and D1b) [13].

Therefore, it has been hypothesized that the A allele encodes cyclin D1b isoform with a longer half-life, thus possibly allowing an over accumulation of cyclin D1 in the cell leading to premature cell passage through G1/S transition, which results in accumulation of genetic errors, and a selective growth advantage for the altered cells [28].

In our study, the frequencies of cyclin D1 genotypes revealed an increase of GA and AA genotypes in $\mathrm{HCC}$ patients as compared to control group (Table 4). Also individuals with GA genotype had three fold risks to develop HCC while those with AA genotype had nine fold risks to develop HCC (Table 4).

Furthermore, the study showed that there is significant difference between HCC and control groups as regard type of allele (Table 4) and A allele increases the risk of developing $\mathrm{HCC}$ by 3.4 folds (Table 4).

Similar results were obtained by a study reported that CCND1 G870A genotypes increase risk of HCC significantly in Turkish population[21]. These results do not match with a previous study found that the CCND1 G870A genotypes were not associated with HCC susceptibility in Taiwan population [22].

Also our study found that GA and AA genotypes increase risk of HCC significantly by 2.2 folds and 3 folds respectively (compared with GG genotype) moreover our results suggested that the A allele has a dose effect in increasing HCC as risk increased from 2.2 folds for GA genotype to 3 folds to AA genotype supporting the hypothesis that this polymorphism is an individual susceptibility factor in the molecular progression of HCC (Table 4).

Furthermore, the study showed that there is significant difference between $\mathrm{HCV}+\mathrm{ve}$ with $\mathrm{HCC}$ and $\mathrm{HCV}+\mathrm{ve}$ without $\mathrm{HCC}$ groups as regard type of allele (Table 5) and A allele increases the risk of HCC significantly by two folds (Table 5).

\section{CONCLUSION}

It could be concluded that, CCND1 G870 A polymorphism increases the risk of HCC . The A allele has a cumulative dose effect as the risk of HCC increases in individuals of AA genotype more than individuals of GA genotype when we used GG genotype as a reference.

Conflicts of interest: None

Funding:None.

Ethical approval:Approved.

\section{REFERENCES}

1- Bray F ,Pisani P. GLOBOCAN 2000: Cancer incidence, mortality and prevalence worldwide, version 1.0. International Agency for Research of Cancer Base 2010; 5. Lyon, France IARC press.

2- Farazi PA, DePinho RA. Hepatoceullar carcinoma pathogenesis: from genes to environment. Nat. Rev. Cancer 2006;6: 674-87.

3- Aravalli RN, Steer CJ, Cressman EN. Molecular carcinoma. Hepatology 2008; 48: 2047-63.

4- Zekri AR, Bahnassy AA, Abdel-Wahab SA, Khafagy MM, Loutfy SA, Radwan H,Shaarawy SM. Expression of pro-and anti-inflammatory cytokines in relation to apoptotic genes in Egyptian Liver Disease patients associated with HCV-genotype 4. J. Gastroenterol. Hepatol.2009; 24: 416-428.

5- Kato N, Ji G, Wang Y, Baba M, Hoshida Y, Otsuka $\mathrm{M}$ et al . Large-scale search of single nucleotide polymorphism for hepatocellular carcinoma susceptibility genes in patients with hepatitis C. Hepatology 2005; 42: 846-53.

6- Tsai MH, Tsai CW, Tsou YA, Hua CH, Hsu CF, Bau DT. Significant association of cycline D1 single nucleotide polymorphisms with oral cancer in Taiwan. Anticancer Res. 2011; 31(1): 227-31.

7- Bonilla C, Lefèvre JH, Winney B, Johnstone E, Tonks S, Colas C et al. Cyclin D1 rare variation in UK multiple adenoma and early onset colorectal cancer patients. J. Hum. Genet 2011; 56(1): 5863.

8- Yuan L, Gu X, Shao J, Wang M, Wang M, Zhu Q, Zhang Z. Cyclin D1 G870 A polymorphism is associated with risk and clinicopathologic characteristics of bladder cancer. DNA cell Biol. 2010; 29(10): 611-7.

9- Yaylim-Eraltan I, Ergen A, Görmüs U, Arikan S, Küçücük $\mathrm{S}$, Sahin $\mathrm{O}$ et al.Breast cancer and cyclin D1 gene polymorphism in Turkish women. In Vivo 2009; 23 (5): 767-72.

10- Witzel LL, Koh LF, Perkins ND . Regulation of cyclin D1 gene expansion. Biochem. Soc. Trans. 2010;38: 217-22.

11- Callender T, El-Naggar AK, Lee MS, Frankenthaler R, Luna MA , Batsakis JG . PRAD-1(CCND1) /cyclin D1 oncogene amplification in primary head and neck squamous cell carcinoma. Cancer 1994;74: 152-8.

12- Musgroue EA, Caldon CE, Banaclough J. Stone A ,Sutherland RL. Cyclin D as a therapeutic target in cancer. Nat. Rev. Cancer.2011; 11: 55872 . 
13- Knudsen KE . The cycline D1b splice variant an old oncogene learns now tricks .Cell Div 2006; 24:1-15.

14- Soloman DA, Wang. Y, Fox S.R . Splice variants differential effects on localization, RB phosphorylation and cellular transformation. $J$. Biochem.2014; 278. 30339-47.

15- Mueller GC, Hussain HK, Carlos RC, Nghiem HV, Francis IR. . Effectiveness of MR imaging in characterizing small hepatic lesions: routine versus expert interpretation. Am. J. Roentgenol 2003; 180: 673-680.

16- Betticher DC, Tacher N, Altermatt HJ, Hoban P, Ryder WD, Heighway J. Alternatives splicing produces a novel cyclin D1 transcript. Oncogen 1995;. 7; 11(5):1005-11.

17- Kim, Y , Lee. H . Single nucleotide polymerphism associated with hepatocellular carcinoma in patients with chronic hepatitis B virus injection. Inventirology 2005; 48: 10-5.

18- Hsia, TC, Liu, CH . Interaction of CCND1 genotype and smoking habit in Taiwan lung cancer patients. Anticancer Res.2011; 31(10): 3601-5.

19- Zekri, A, Hafez, M , Banhawy, A . Genetic profile of Egyptian hepatocellular carcinoma associated with hepatitis $\mathrm{C}$ virus genotype 4 by $15 \mathrm{k}$ CDNA microsomy: preliminary study .BMC Res. Notes 2008; 1:1016.

20- Guo Y, Yang K, Harwalkar J, Nye JM, Mason DR, Garrett MD et al. Phosphorylation of cyclin D1 at Thr 286 during sphase lead to its proteasonal degradation. Oncogene 2005; 24: 2599-612.

21- Akkiz H, Bayram S, Bekar A, Akgöllü E, Ozdil B. Cyclin D1 G870A polymerphism is associated with an increased risk of hepatocellular carcinoma in Turkish population: Case-Control Study. Cancer Epidemiology 2010; 34(3):298-302.
22- Zhangyang, H, Zhipeng, Z, Guolian, X, Jinliang Y - Cycline D1 G870A polymorphism Chinese Population. Tumor Biol 2014; 35: 807-5612.

23- El-Serag HB. Hepatocellular carcinoma. N Engl J Med 2011; 365: 1118-27.

24- Tomoki, N; Toshiaki, N ,Junko, Y . Greater age and hepatocellular aging are independent risk factors for hepatocellular carcinoma arising from non-B non-C non-alcoholic chronic liver disease. Pathology International 2011; 61: 572-576.

25- Ehab F, Ghada M, Galal B. Smoking and the risk of hepatocellular carcinoma among Egyptian patients. A preliminary case-control study. Arab Journal of Gastroenterology 2009; 10(1016): AB53 - AB60.

26- El-Serag HB; Hampel H; Javadi F. The association between diabetes and hepatocellular carcinoma: a systematic review of epidemiologic evidence. Clin Gastroenterol Hepatol 2006;4:369-80.

27- Fattovich G, Stroffolini T, Zagni I, Donato F. . Hepatocellular carcinoma in cirrhosis: incidence and risk factors. Gastroenterology 2004; 127(5 Suppl 1):S35-S50.

28- Guo Y, Yang K, Harwalkar J, Nye JM, Mason DR, Garrett MD et al. Phosphorylation of cyclin D1 at Thr 286 during $S$ phase leads to its proteasomal degradation and allows efficient DNA synthesis. Oncogene 2005; 24: 2599-612.

Peer reviewer: Nahla Elgammal, Professor of Tropical Medicine and Hepatogastroenterology, Faculty of Medicine, Zagazig University, Egypt. Editor: Tarik Zaher, Professor of Tropical Medicine and Hepatogastroenterology , Faculty of Medicine, Zagazig University, Egypt. 